\title{
Influence of temperature on pyrolysis of waste tire under nitrogen atmosphere
}

\author{
Yongjuan Dai ${ }^{1,2, a}$ Guohao Zhang $^{1}$ Chi Zhang $^{1}$ Guanxu Zhang ${ }^{1}$ Dengjie You ${ }^{1}$ \\ 1 College of Materials science and engineering, Hebei university of science and technology, \\ Shijiazhuang 050018, Hebei, China; \\ 2 Hebei key laboratory of material near-net forming technology, Hebei university of science and \\ technology, Shijiazhuang 050018,Hebei, China \\ adai951236@163.com
}

Keywords: pyrolysis, nitrogen atmosphere, temperature, waste tire

\begin{abstract}
An experimental survey of waste tire gasification under nitrogen atmosphere has been conducted in a reactor, the gasification of tire were performed in a series of trials at different processing temperatures, in the range of $100-800{ }^{\circ} \mathrm{C}$, with the aim of studying the influence of the process temperature on the yield and the composition of the products. The experimental results showed that thermal stability of waste tire is divided into 3 zone: $\sim 200{ }^{\circ} \mathrm{C}, 200{ }^{\circ} \mathrm{C}$ to $300^{\circ} \mathrm{C}$ and $300^{\circ} \mathrm{C}-800^{\circ} \mathrm{C}$. A higher temperature results in a higher syngas production and a lower char yield, due to an enhancement of the solid - gas phase reactions with the temperature. Under $\mathrm{N}_{2}$ conditions, the oil contains more light oil.
\end{abstract}

\section{Introduction}

The use of renewable sources and waste valorisation is increasing because of several factors, which include global warming, negative environmental impact due to the use of fossil fuels and the increase of energy demand and availability of waste materials. Therefore, it is necessary to study how to improve current processes to obtain an energy benefit with aminimum of environmental impact. Waste tires pose significant health and environmental concerns if not recycled and/or discarded properly. Tyre pyrolysis is designed to recover valuable fractions clean and efficiently while minimising energy valorisation, as highlighted in the laws governing waste treatment.

Pyrolysis valorisation process shows some advantages (environmental and technical) with respect to other valorisation processes. The most important one is the production of a liquid fuel that can be easily stored and transported. In addition to this liquid fraction, solid and gas fractions are produced, which can also be used as fuels (solid and gas fractions) or be valorised for the production of activated carbon (solid fraction)[1].

Inert gas pyrolysis technology refers to the tire pyrolysis under inert gas protect or inert gas is used for the reactant blow, the method can greatly reduce the volatile phase product in the reactor[2]. In the paper, the influence of temperature on pyrolysis of waste tire under nitrogen atmosphere has been studied. The study of pyrolysis processes to find the best operational conditions is of great interest for designer of reactor and optimization of wast tire pyrosis process..

\section{Experimental procedure}

The waste tire used for the experimental work were cut to granulated tire. Granulated tire samples of maximum $10 \mathrm{~mm}$ mean diameter were selected and kept at ambient conditions. About $100 \mathrm{~g}$ of material was used for each test.

The schematic diagram of the experimental device is reported in Fig. 1. The gasification tests were conducted on a bench scale apparatus designed and assembled by ourself.

Fixed bed, batch reactors have been widely used to investigate pyrolysis of waste tyres. The reactor is typically heated externally by an electric furnace and nitrogen gas is used as a carrier gas. 
The derived gas products are carried by the carrier gas and condensed downstream and the non-condensable gases are collected and analysed. The residual char and any steel are collected after experimentation.

In any test, nitrogen was used as atmosphere and carrier gas, to create free of oxygon and safety working conditions. The carrier gas N2 provided by cylinder. Before starting the gasification experiments, the initial nitrogen flow rate was maintained at $1.5 \mathrm{dm} 3 \mathrm{~min}-1$ to completely purge the system till the prescribed process temperature was reached.

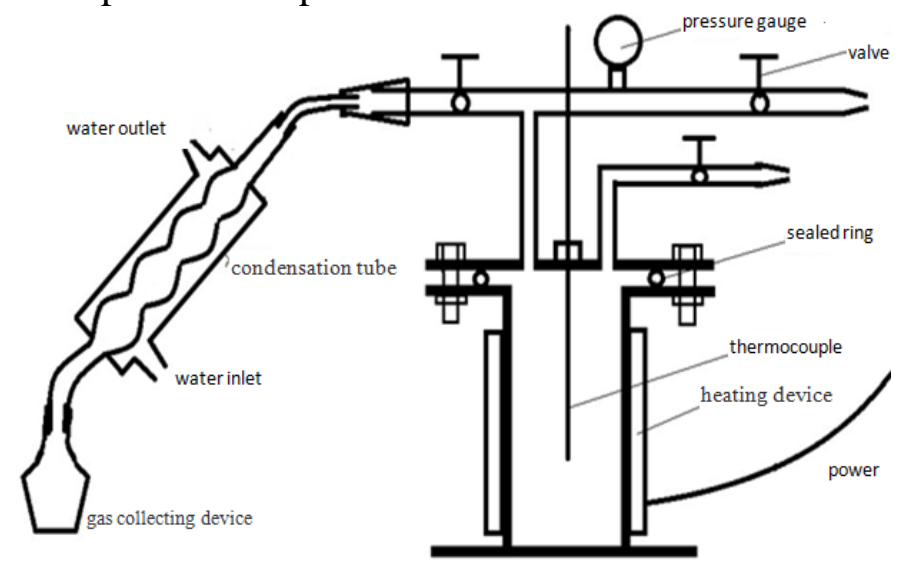

Fig.1. Experimental device

\section{Results and Discussion}

\section{Thermal stability of waste tire}

To understand thermal stability of waste tire, the gasification of tire were performed in a series of trials at different processing temperatures, in the range of $100-800^{\circ} \mathrm{C}$, holding all the other operational parameters constant. The pyrolysis temperature is every $50^{\circ} \mathrm{C}$ as a gauge between $100{ }^{\circ} \mathrm{C}$ to $800^{\circ} \mathrm{C}$ and the holding time is 60 minutes. Pyrolysis experiments of powder sample (without adding catalyst) were performed.

The results showed that, below $200{ }^{\circ} \mathrm{C}$ powder sample had basically no decomposition. Between $200{ }^{\circ} \mathrm{C}$ to $300{ }^{\circ} \mathrm{C}$, the majority of oil are condensed on the wall of the heating device due to incomplete pyrolysis, and the pyrolysis oil is black and sticky, the remaining solid is not completely decomposed. The remains is hard, it is not pure char. This is incomplete pyrolysis process. When the pyrolysis temperature is above $300{ }^{\circ} \mathrm{C}$ and especially above $350{ }^{\circ} \mathrm{C}$, there is no black sticky oil condenses on the tube. The collected pyrolysis oil is fluidity, the upper layer is light yellow, transparent, the under layer is black or brown. The solid remains is powder char, it can be crumbed by hand. Gas products has the smell of oil. With the increase of temperature, oil production increased, but its fluidity and color has little changes.

At $200{ }^{\circ} \mathrm{C} \sim 300{ }^{\circ} \mathrm{C}$, rubber intrinsic viscosity change rapidly, low molecular material is "hot distilled out", and the residue was becoming insoluble dry matter. At this temperature zone, some of the rubber polymer chain have not yet broken, some of them fracture and become relatively large molecular chemicals, thus resulting in the black and viscous oil, the formation of char is far from complete. When the temperature is higher than $300{ }^{\circ} \mathrm{C}$, rubber decomposition accelerate, break out of the chemical substances is smaller molecular material, resulting in the oil transparent oil[3].

According to the tests performed at different temperatures, thermal stability of waste tire is divided into 3 zone: $\sim 200{ }^{\circ} \mathrm{C}, 200{ }^{\circ} \mathrm{C}$ to $300{ }^{\circ} \mathrm{C}$ and above $300{ }^{\circ} \mathrm{C}$ to $800{ }^{\circ} \mathrm{C}$. Then the pyrolysis temperature is above $300^{\circ} \mathrm{C}$ or even $350^{\circ} \mathrm{C}$ at less.

\section{Influence of temperature on pyrolysis of waste tire}

The thermally degradation of the tire starts at around $350^{\circ} \mathrm{C}$ and therefore pyrolysis experiments are in the range of $350^{\circ} \mathrm{C}-800{ }^{\circ} \mathrm{C}$.To research the influence of temperature on pyrolysis of waste tire, experiments performed at low temperature zone $350{ }^{\circ} \mathrm{C}-450^{\circ} \mathrm{C}$, middle temperature zone $450^{\circ} \mathrm{C}$ - 
$600^{\circ} \mathrm{C}$ and higher temperature zone $600^{\circ} \mathrm{C}-750^{\circ} \mathrm{C}$. Table 1 shows the yields of oil, char and gas from the process.

Table1 the yields of oil, char and gas from the process

\begin{tabular}{|c|c|c|c|}
\hline Temperature & Oil & Char & Gas \\
\hline 400 & 38.4 & 44.8 & 16.8 \\
\hline 550 & 45.9 & 36.9 & 17.2 \\
\hline 750 & 44.9 & 34.5 & 20.6 \\
\hline
\end{tabular}

It should be noted that raising the temperature in a fixed reactor system beyond where the rubber has been thermally degraded increases the yield of oil and gases. These oils and gases are most probably produced from the volatilisation of some of the solid, very higher molecular hydrocarbon content of the char reports the yields of the process fractions (char, oil, and gas) at different temperatures. Furthermore, as expected, rising the temperature, the gas yield progressively increases while char and oils yields decrease; the temperature effect mainly affects the condensable fraction more than the solid residue indicating an increase of the secondary cracking reactions in vapor phase.

This situation is probably dependent on the more favorable thermal cracking reactions that were caused by higher temperatures, which result in the major extensions of the secondary cracking reactions into the gas fraction

The experimental results show that a higher temperature results in a higher syngas production and a lower char yield, due to an enhancement of the solid-gas phase reactions with the temperature. Furthermore, in regards to the elemental composition of the synthesis gas[4], as the temperature increases, the carbon content continuously decreases, the hydrogen, being the main component of the gas fraction and having a small atomic weight, is responsible for the progressive reduction of the gas density at higher temperature.

In regard to the gas fraction, the principal components (apart from nitrogen, which was used as the carrier gas), detected over the different trials and reported[5], were $\mathrm{H}_{2}, \mathrm{CH}_{4}, \mathrm{CO}, \mathrm{CO}_{2}$, and small quantities of some hydrocarbons, such as ethane, ethylene, and acetylene. Higher temperatures clearly result in higher hydrogen concentrations; the hydrogen content rapidly increases, attaining values higher than $65 \%$, while methane and ethylene gradually decrease over the range of the temperatures; carbon monoxide and dioxide instead, after an initial increase, show a nearly constant concentration[6]

Furthermore, in regards to the elemental composition of the synthesis gas, as the temperature increases, the carbon content continuously decreases, the yield of the fuel oil increased from 33. $1 \% \sim 35.4 \%$ to $43.2 \% \sim 45.1 \%$ as the pyrolysis temperature increased from $4500^{\circ} \mathrm{C} \sim 550^{\circ} \mathrm{C}$ to $650^{\circ} \mathrm{C} \sim 750^{\circ} \mathrm{C}$. On the contrary, the yield of carbon black decreased from $46.2 \% \sim 49$. $2 \%$ to 35 . $1 \% \sim 37.1 \% \mathrm{w}$ ith the increasing of the temperature[7]. The repot result is agree with our experiment.

The experimental results show that a higher temperature results in a higher syngas production and a lower char yield, due to an enhancement of the solid-gas phase reactions with the temperature.

\section{Influence of nitrogen atmosphere}

Inert gas pyrolysis technology refers to the tire pyrolysis under inert gas protect or inert gas is used for the reactant blow, the method can greatly reduce the volatile phase product in the reactor. Residence time and suppression of two cleavage volatile phase products, so as to improve the yield of pyrolysis oil.

Among the pyrolysis oil, boiling point of $45 \sim 205{ }^{\circ} \mathrm{C}$ for light oil (equivalent to the gasoline fraction), $205 \sim 365{ }^{\circ} \mathrm{C}$ for the quality of oil (diesel equivalent fractions), $>365{ }^{\circ} \mathrm{C}$ for heavy oil (heavy oil fractions). Light oil content increases with temperature rise. High quality content in the oil changes little with temperature, and heavy oil content decreases with increasing temperature[8].

Compared $\mathrm{N}_{2}$ atmosphere, $\mathrm{H}_{2}$ and $\mathrm{H}_{2} \mathrm{O}$ atmosphere usually give less light oil and more heavy oil, Compared to heavy oil, light oil has higher utilization value, and therefore in terms of the use of oil, $\mathrm{N}_{2}$ strip is helpful in getting high-value oil. 
The presence of a $\mathrm{N}_{2}$ carrier gas on oil yield has effect on the yield of pyrolysis oil larger, the method can greatly reduce the volatile phase product in the reactor. Under $\mathrm{N}_{2}$ conditions, the oil contains more light oil, light oil is rich in high value-added chemicals limonene, raising the temperature of the oil can increase the amount of light.

\section{Summary}

An experimental survey of waste tire gasification under nitrogen atmosphere has been conducted in a reactor, with the aim of studying the influence of the process temperature on the yield and the composition of the products; the tests have been performed at different temperatures, the summary as follow.

(1) Thermal stability of waste tire is divided into 3 zone: room temperature to $200{ }^{\circ} \mathrm{C}, 200{ }^{\circ} \mathrm{C}$ to $300^{\circ} \mathrm{C}$ and above $300^{\circ} \mathrm{C}$. The obviously thermally degradation of the tire starts at around $350^{\circ} \mathrm{C}$ and therefore pyrolysis experiments are in the range of $350^{\circ} \mathrm{C}-800{ }^{\circ} \mathrm{C}$.

(2) The experimental results show that a higher temperature results in a higher syngas production and a lower char yield, due to an enhancement of the solid-gas phase reactions with the temperature, and the oil yield is highest when the pyrolysis is about $550^{\circ} \mathrm{C}$.

(3) The $\mathrm{N}_{2}$ strip improve the yield of pyrolysis oil. it is helpful in getting high-value oil.

\section{Acknowledgements}

This work was financially supported by Students provincial innovation and entrepreneurship training project(201310082033).

\section{References}

[1] M. Kyari, A. Cunliffe, P.T. Williams. Energy\& Fuel 19 (2005) 1165-1173.

[2] J.M. Bouvier, M. Gelus. Resources and Conservation 12 (1986) 77-93.

[3] S. Portofino, A. Donatelli, P. Iovane. Waste Management 33 (2013) 672-678.

[4] P.T. Williams. Waste Management 33 (2013) 1714-1728.

[5] R.Aguado, A.Arrizabalaga, M.Arabiourrutia. Chemical EngineeringScience106(2014)9-17

[6] H.Ayd, Cumal. Fuel 102 (2012) 605-612

[7] M.Miranda, F.Pinto, I, Gulyurtlu. Fuel 103 (2013) 542-552

[8] A.Quek, R.Balasubramanian. Journal of Analytical and Applied Pyrolysis 101 (2013) 1-16 